\title{
SENTIDO E HIPERTEXTO
}

\section{SENSE AND HIPERTEXT}

Tânia Aiub

Instituto Federal de Educação, Ciência e Tecnologia, Osório, RS, Brasil Universidade Federal do Rio Grande do Sul, Programa de Pós-Graduação em

Letras, Porto Alegre, RS, Brasil

Resumo: Vinculada à Análise de Discurso, esta escrita pretende criar um espaço de reflexão sobre a produção de sentidos a partir de uma textualidade que tensiona as clássicas noçôes de texto e de sentido: falamos do conceito de hipertexto e da dinâmica específica de leitura que ele proporciona através do processo de linkagem.

Palavras- chave: texto; hipertexto; discurso; legibilidade.

Abstract: Inscribed in the Field of Discourse Analysis this investigation proposes to create a space of reflection on the production of senses considering an approach that challenges the classic notions of text and meaning: we refer to the conception of hypertext and to the specificities of the dynamic of reading that are produced by the process of linking.

Keywords: hipertext; discourse; legibility.

\section{Consideraçóes iniciais}

À luz da Análise de Discurso (AD), uma característica salutar do conceito de texto e de textualidade é a fragmentação da noção de univocidade. Essa teoria confronta qualquer concepção de centramento e unilateralidade na produção de sentidos; porquanto, exige que tomemos o conceito de texto a partir do entendimento do "efeito" decorrente de certo modo de compreender a materialidade linguística como suporte de processos discursivo-ideológicos de produção de sentido. Cabe observar, da perspectiva em que nos colocamos neste texto, os modos de constituição de sentidos na dinâmica de leitura específica dos ambientes digitais, especificamente do hipertexto, a partir do processo de navegação por janelas sobrepostas de textos. A prática da leitura-navegaçáo instiga-nos a pensar sobre a legibilidade e sobre as condiçóes do legível no espaço de construção hipertextual, sobretudo, na condição do sujeito-leitor investido de uma posiçẫo-sujeito que, ao navegar, está produzindo um percurso de leitura próprio. 


\section{Análise de discurso: o efeito-texto}

Em $\mathrm{AD}$, a materialidade da língua é conjugada à materialidade da história e à ideologia. $\mathrm{O}$ conceito de discurso pauta-se na existência de um sujeito enunciador que está condicionado por suas relaçôes históricas (formaçóes sociais) e ideológicas (representações de suas relaçôes no campo da prática). Parte-se, portanto, da concepção de que o sujeito não recebe, tampouco manipula a língua como se esta fosse um mero instrumento comunicativo; trata-se, outrossim, de um sujeito que faz sentido quando investido de uma função simbólica, quando ocupa uma posição enunciativa (posição-sujeito) que, invariavelmente, náo depende de sua "escolha", mas é efeito de seus processos de formação no campo da prática social, política e ideológica. O conceito de escolha para o indivíduo investido de uma posição-sujeito é um efeito imaginário, necessário à tomada de posição e ao reconhecimento dos lugares enunciativos.

$\mathrm{Na}$ medida em que assumimos o ponto de vista sócio-histórico, precisamos considerar o conceito de texto em sua historicidade e, além disso, considerar texto como efeito do acontecimento enunciativo, pautado na historicidade do sujeito em sua tomada de posição no ato de enunciar. Mas, é preciso levar em conta que o caráter histórico da enunciação, da tomada de posição, nos termos que aqui se colocam, não condiz com a temporalidade do ato, uma vez que não se trata do tempo da enunciação. $\mathrm{O}$ caráter histórico da enunciação, em $\mathrm{AD}$, está relacionado às condiçóes sociais, ideológicas de constituição do sujeito que enuncia.

O aspecto sócio-histórico que permeia a definição do objeto texto pontua que a evidência do texto como objeto puramente linguístico é, para $\mathrm{AD}$, efeito imaginário, definido pelo ideal de transparência, de univocidade e de língua como instrumento neutro de comunicação. Guimarães (1995) sintetiza muito bem esse imaginário quando refere que:

\footnotetext{
Texto tem a ver com a ilusáo de evidência ligada ao fato de que há sequências de linguagem que se caracterizam por ter um princípio e um fim. Esta evidência está ligada ao fato de que em dadas circunstâncias, começa-se a escrever e termina-se. (GUIMARÃES, 1995, p. 64, grifo nosso).
}

O texto deve ser tomado, portanto, sob alguns pontos de vista característicos da análise de discurso: 
a) Como unidade discursiva;

b) Como efeito de uma prática social caracterizada pelo ato de um indivíduo investir-se de uma posição-sujeito para enunciar;

c) Como relação de sentidos imaginários, efeitos das projeçôes imaginárias (formaçôes imaginárias) que o sujeito enunciador produz no ato de enunciaçáo.

O que até aqui se colocou nos conduz ao essencial da teoria do discurso AD: o objeto desta teoria é o discurso, conceituado como efeito de sentido entre sujeitos. Pêcheux (1997) formula o conceito de efeito de sentido a partir da consideração dos lugares sociais e ideológicos e das projeçôes imaginárias a partir dos quais a língua é mobilizada. $\mathrm{O}$ texto, por conseguinte, é a materialidade pela qual o analista acede ao processo discursivo de constituiçấo dos efeitos de sentido. Isso faz com que o texto e os aspectos de textualidade que lhe dão forma náo sejam tomados puramente do ponto de vista da organização linear e sistemática das relaçôes linguísticas. Mas, sobretudo, deve ser tomado com base em condiçôes de produçáo do discurso e de seus efeitos.

Essa relação da textualidade com as condiçóes de produção leva ao conceito de textualização ${ }^{1}$, ou seja, o texto, como efeito de um trabalho simbólico, passa a engendrar relaçóes que não são de ordem puramente interna, visto que, "para a Análise do Discurso, a organização linguística interna ao texto é o que menos interessa" (INDURSKY, 2001, p. 28).

A textualizaçáo difere do conceito de textualidade por estar relacionada a exterioridades constitutivas do processo discursivo-enunciativo de produção textual. Expliquemo-nos: para que haja textualidade - qualidade de ser texto (HALLIDAY; HASSAN, 1976) - as linguísticas de texto (doravante LT) cunharam dois conceitos-chave: o de coesão e o de coerência, desvinculados de qualquer base histórica e social. Esses conceitos dáo conta de uma organização interna do texto e o mais próximo que estiveram de uma noção de exterioridade foi através do conceito de contexto, restrito a uma situação de comunicação, extremamente pragmática e a-histórica.

A textualização, por sua vez, engendra relaçôes discursivas, exteriores ao entrelaçamento endofórico do texto, já que consideram a multiplicidade relacional entre discursos, subjetividades, posiçôes históricas, os quais

${ }^{1} \mathrm{O}$ conceito de textualização é inserido no campo teórico da $\mathrm{AD}$ a partir da tese de doutoramento de Solange Gallo, intitulada “Texto: como apre(e)ender essa matéria?” (IEL, Unicamp, 1994). 
permeiam os processos de escrita e de leitura. O texto torna-se um ponto numa rede associativa de sentidos, de outros textos que, por sua vez, são de outros processos discursivos. Esse efeito-texto é resultado de uma evidência produzida silenciosamente como o efeito-sujeito e o efeito de sentido. Ele resulta da ilusão de completude do texto, da evidência do ego quando este se diz estar na origem dos sentidos. Ilusão necessária para autores e leitores que se representam imaginariamente na origem de seu dizer.

Ordenando as ideias aqui propostas temos que: o texto é a materialidade do discurso enquanto efeito de um processo social, histórico e, portanto, ideológico de constituição de sentidos. Isso é produto do trabalho simbólico de sujeitos que ocupam posiçóes de enunciação definidas pelo campo das práticas política e histórica, em que a cada um são determinados lugares ideologicamente constituídos. Esses lugares são reconhecidos, e os sentidos, então, geram o efeito de pertencimento de indivíduos a realidades sociais. Contudo, os sentimentos de reconhecimento e pertencimento são evidências ideológicas, ou seja, são produtos da representação imaginária que os indivíduos elaboram sobre suas relaçóes no campo da prática.

Diante disso, cabe orientar a proposta desta escrita: ao tomarmos o hipertexto como unidade de análise, pode-se dimensionar os processos de leitura-navegação do hiperleitor do ponto de vista da relaçáo com o conceito de posição-sujeito? O hiperleitor pode ser, pelo ato de navegação inerente às estruturas hispertextuais, autor de novos processos enunciativos? Considerado o conceito de autoria como uma tomada de posiçáo numa rede interdiscursiva, o conceito de legibilidade passa a realizar-se por outra ótica: a da constituição do lido no ato mesmo de concepçáo da escrita como efemeridade, como espaço de dizer e de ler.

Passemos ao conceito de hipertexto.

\section{Hipertextos}

O texto clássico é orientado pela lógica do todo e das partes, entendido como dado empírico, constituído de parágrafo, períodos, frases, sílabas e, finalmente, o menor elemento possível de segmentaçáo, que é o fonema ou grafema. Com começo e fim perceptíveis, o texto deve se organizar em torno de um núcleo, manifestação do ideal de unidade temática; em outras palavras, há que se organizar com coesão e coerência. Essa atitude epistêmica orienta as ciências modernas. No entanto, ela vê surgir o hipertexto com a proposiçáo de outro tipo de estrutura: lacunar, aberta, cujas partes náo 
se coordenam linearmente, para a qual inexiste a possibilidade de um leitor passivo e de um autor centralizador do dizer. A tônica recai sobre a irregularidade e não mais sobre a sistematicidade ordenada. Essa mudança de paradigma marca uma significativa reorientação nos parâmetros de escritura e leitura como reação direta à cultura impressa.

$\mathrm{Na}$ perspectiva da conectividade, tudo pode entrar em relação com tudo. Isso implica o reconhecimento de uma transformação na relação do homem com as formas de comunicação. Não há linearidade, nem caminhos fixos a seguir. A separação hierárquica entre texto principal e as anotaçôes fragiliza-se quando um texto está em rede, num mesmo suporte, com outros textos e outros padróes de uso da linguagem propiciados pelas mídias digitais. A relação que se estabelece é de colaboração entre autorias que caracterizam, durante o gesto de navegação, um tipo de escrita colaborativa. Os vetores que produzem o encadeamento entre os textos promovem a corrosão das fronteiras entre textos individuais, ocasionando o descentramento das posiçóes de autoria e de leitura. Landow (1995) traduz esse comportamento colaborativo:

[...] sistemas hipertextuais permitem ao leitor anotar um texto individual e linkar para outros, até textos contraditórios, isso destrói uma das mais importantes características do texto impresso - sua separaçáo e univocalidade. Sempre que colocamos um texto numa rede de outros textos reforçamos a sua existência como parte de um diálogo complexo (LANDOW, 1995, p. 63).

O que possibilita esse processo de conexão e que faz com que uma rede de textos seja um hipertexto é a existência dos hiperlinks (nós - elementos de informação, parágrafos, páginas, imagens, sequências musicais, referências, notas, indicadores, 'botôes' que efetuam a passagem de um nó a outro), os quais trabalham, fundamentalmente, como elementos apontadores de caminhos para navegação na rede. Os hiperlinks são vínculos eletrônicos que permitem a amarração entre vários textos, possibilitando uma rede de sentidos contínuos. Esses nexos eletrônicos conduzem os usuários por distintos trajetos de leitura em um conjunto dado de lexias. A estrutura em rede, o ambiente digital de leitura permitem que janelas de textos organizem-se em torno de um centro semântico, relacionem-se com elementos paratextuais e possibilitem ao leitor-navegador a construção de percursos de leitura próprios - sendo que próprio não significa literal e unívoco. Sem dúvida, o hipertexto traz a possibilidade de compor um texto como um campo disperso de variantes e não como uma estrutura falsamente 
unitária. Segundo Landow (1994, p. 15-16):

Com o hipertexto, me refiro a um meio informático que relaciona informaçáo tanto verbal como não verbal. Os nexos eletrônicos unem lexias tanto externas a uma obra, por exemplo, um comentário desta por outro autor, os textos paralelos ou comparativos, como internas e, assim, criam um texto que o leitor experimenta como náo linear, ou melhor, como multilinear ou multisequencial.

Pierre Lévy (1996), por sua vez, coloca a questão da leitura como a força motriz que faz com que hipertextos não se configurem somente como materialidades digitais, como produtos da informatização. A digitalização e o programa de leitura que encerra predeterminam um conjunto de possíveis que, mesmo imenso, é, sobretudo, numericamente finito e logicamente fechado. É a leitura que realiza o texto. A essência da hipertextualidade está, para tanto, além do suporte mecânico (hardware e software), pois a informática, por si, oferece combinatórias que não problematizam em nada a questão do sentido. Isso é potencial, $\mathrm{o}(\mathrm{s})$ texto(s) existe(m) aí em potência. Não são as inúmeras possibilidades de associaçôes que dão essência ao modo virtual de fazer sentido. A virtualização extrapola os limites binários quando é trabalhada pelo sujeito. Para o autor, portanto:

Um hipertexto é uma matriz de textos potenciais, sendo que alguns deles vão se realizar sob o efeito da interação com um usuário. Nenhuma diferença se introduz entre um texto possível da combinatória e um texto real que está na tela. A maior parte dos programas são máquinas de exibir (realizar) mensagens (textos, imagens etc.) a partir de um dispositivo computacional que determina um universo de possíveis. Esse universo pode ser imenso, ou fazer intervir procedimentos aleatórios, mas ainda assim é inteiramente précontido, calculável (LÉVY, 1996, p. 40).

A presença de múltiplos trajetos de leitura perturba o equilíbrio entre leitor e escritor rompendo as barreiras que os colocam como individualidades produtoras de sentido. À medida em que o leitor move-se por uma rede de textos, desloca constantemente o centro e, com ele, desloca a noção de estrutura estável de textualidade. Sua experiência de leitura converte-se igualmente em processo enunciativo tanto quanto em processo de escritura. Subjacente a essa mobilidade do gesto de leitura-navegaçáo, temos um centro móvel do texto que depende de um leitor que é, a um só tempo, autor de novos processos enunciativos. 
Se definirmos o hipertexto como um espaço de percurso para leituras possíveis, um texto aparece como uma leitura particular de um hipertexto. O navegador participa, portanto, da "redação" do texto que lê. Tudo se dá como se o autor de um hipertexto constituísse "uma matriz de textos potenciais", o papel dos navegantes sendo o de realizar alguns desses textos colocando em jogo, cada qual à sua maneira, a combinatória entre os nós. $\mathrm{O}$ hipertexto opera a virtualização do texto (LÉVY, 1999, p. 57).

O espaço do sentido não preexiste à leitura. Isso é fato inconteste para qualquer texto, em qualquer suporte, pois o leitor tem diante de si o que Lévy (1999, p. 35) configura por "uma paisagem semântica móvel e acidentada em que o texto é esburacado, riscado, semeado de brancos". Para o autor, ainda, enquanto leitores, "podemos desobedecer às instruçôes, tomar caminhos transversais, produzir dobras interditas, estabelecer redes secretas, clandestinas, fazer emergir outras geografias semânticas" (LÉVY, 1999, p. 35). E, fundamentalmente, essa atualizaçáo, essa viagem por percursos semânticos únicos não se realiza para retornar ao pensamento de um autor, mas para fazer do texto atual parte de um campo textual maior, móvel, reconfigurável.

\section{Hiperleitura: a condiçáo do legível na navegaçáo hipertextual}

A partir do exposto, temos uma teoria que propóe a textualidade como efeito da constituição simbólica do sujeito e do sentido. Temos a afirmação categórica de que o trabalho sobre os sentidos na materialidade textual é um trabalho sócio-histórico de posiçóes-sujeito. Abordaremos, portanto, a leitura em hipertexto através do processo de linkagem e construção de uma rede hipertextual, como efeito do trabalho de um sujeito que se investe da posição-sujeito para gerar efeitos de sentido. Tomaremos o conceito de legibilidade para pontuar o recorte específico de leitura com que estamos trabalhando neste artigo: a leitura-navegação que, de nosso ponto de vista, converte-se em processo autoral de constituição de hipertextos.

A legibilidade é um conceito móbil para a abordagem de textos. Primeiramente fundamentado na orientação de que texto é uma totalidade que está a serviço de um autor, sendo que este conceito reproduz os parâmetros das linguísticas de texto, o qual destina seu "produto" a um leitor que, onipotente, desvendará o sentido (único) direcionado. Por outro lado, a condição do ser ou não legível abre um espaço de reflexão para os 
estudos da linguagem quando estâo em tela as condiçóes de produção da materialidade legível e as posiçóes subjetivas envolvidas na enunciação.

Haroche (1992) liga a questão da legibilidade à busca ideológica de individualização e isolamento do sujeito. A busca pela transparência e completude surge, para a autora, da necessidade latente de uniformização do sujeito, que individualizado, homogeneizado, segundo as regras que a "língua" the impóe, é assim responsabilizado. Isso implica a visibilidade do sujeito que mobiliza a língua, visibilidade essa que gera para ele a necessidade de produção de um discurso linear e claro, correspondente ao ideal de dizer "completo" e encerrado. Isso leva a uma caça ao indeterminado semanticamente, ao impensado que não se mostra:

A caça incessante à ambiguidade, à elipse (à falta) à incisa (ao acréscimo descontrolado) e, de maneira geral, a tudo que pode parecer uma zona de sombra nascida de uma ruptura a linearidade do discurso, participa desta exigência de legibilidade. Visibilidade isolante e legibilidade isolante (HAROCHE, 1992, p. 23).

Nesse caso, a questão da legibilidade é um problema com que a $\mathrm{AD}$ se depara e para o qual lança outro ponto de vista, ligado à questáo do texto como efeito, pois pensar que um texto para ser texto deve ser legível requer que tenhamos em conta outros fatores como: o texto é legível para quem?; Em que condiçôes um texto é legível? Isso deixa em aberto questôes acerca do que se entende por condiçấo de legível da materialidade linguística. Incidiremos sobre a relatividade que o termo legibilidade adquire na $\mathrm{AD}$ :

[...] de um lado, a legibilidade não é uma questáo de tudo ou nada, mas uma questão de graus, e, de outro, gostaríamos de dizer que a legibilidade envolve outros elementos além da boa formação de sentenças, da coesão textual, da coerência (ORLANDI, 1996, p. 183).

Para Orlandi (1996), pensar em questóes como "O que torna um texto legível?" ou "O que é um texto legível?” está numa escala mais complexa de entendimento do que seja texto e sentido, bem como do que sejam as atividades de escritura e leitura. Significa, direcionando um olhar discursivo sobre o texto e sobre os processos que nele e por ele se instauram, que a legibilidade não está no objeto texto, como se fosse um ingrediente que lhe conferisse o sucesso de ser ou não texto. Pelo contrário, a legibilidade está e, ao mesmo tempo, não está no texto. Não se trata de uma "consequência direta, unilateral e automática da escrita” (ORLANDI, 1988, p. 8, grifos 
nossos), mas trata-se de uma relação relativizada sempre por condiçóes de produçáo, tanto da escritura quanto da leitura que se empreende sobre a superfície linguística. Assim "é a natureza da relação que alguém estabelece com o texto que está na base da caracterização da legibilidade" (ORLANDI, 1988, p. 9).

Não sendo a legibilidade uma consequência direta e unilateral da escrita, ela ultrapassa os limites presos ao próprio objeto. Pode-se, portanto, compreender que a relação texto/não-texto não pode estar barrada (tal como em LT), mas deve ser tida como uma relação de constituição. O texto contém em si o não-texto, já que os critérios de textualidade relativizamse, sendo "uma questáo de natureza, de condiçóes, de modos de relaçáo, de trabalho, de produção de sentidos, em uma palavra: de historicidade" (ORLANDI, 1988, p. 9).

Isso mostra como a escritura e a leitura podem ser processos complexos que estão além do desenvolvimento de habilidades linguísticas, além do domínio das formas da língua. Trata-se de processos indistintos, pois escrever é ler (re-ler) e ler é escrever (produção de sentidos), ambos processos em busca do que o texto diz e do que náo diz, sendo, por isso, processos eminentemente interpretativos. Leitura e escritura, nesses termos, não são relaçóes que ocorrem individualizadas entre leitor-texto e entre autor-texto, como se ambos processos tivessem sua ocorrência entre sujeitoobjeto. Trata-se, sobretudo, de uma relaçáo entre sujeitos (autor - leitor virtual - leitor real ${ }^{2}$ ) em que o texto é objeto mediador para a constituição de sentidos. Segundo Orlandi (1998, p. 9):

O leitor não interage com o texto (relação sujeito/objeto), mas com outro(s) sujeito(s) (leitor virtual, autor, etc). A relaçáo, como diria A. Schaff (em sua crítica ao fetichismo sígnico, 1966), sempre se dá entre homens, são relaçôes sociais; eu acrescentaria, históricas, ainda que (ou porque) mediadas por objetos (como o texto). Ficar na 'objetalidade' do texto, no entanto, é fixar-se na mediação, absolutizando-a, perdendo a historicidade dele, logo, sua significância.

\footnotetext{
${ }^{2}$ Orlandi descreve a existência de duas categorias de leitor com os quais o autor do texto entra em interlocução. Primeiramente, tendo como base as formaçóes imaginárias, o autor pressupóe um leitor (leitor-virtual), que seria o sujeito para quem destina seu texto. Essa é uma categoria de leitor inscrita no texto, constituída no próprio ato da escrita. No entanto, o texto, no processo de leitura, entra em relação direta com leitores reais, os quais estão em interlocução com este leitor-virtual. Por isso, a relação de produção de sentidos dá-se entre sujeitos, mas nunca numa relação biunívoca entre sujeito e objeto.
} 
$\mathrm{Na}$ medida em que os interlocutores (leitor real - leitor virtual autor) encontram-se, começa um constante debate, pois as condiçóes de produção da escritura do texto nem sempre estáo em relação harmônica com as condições de produção da(s) leitura(s) possíveis. A única relação que pode ser seguramente harmônica é a relação do autor com seu leitor virtual, pois essa relação está no nível das projeçôes, das formaçôes imaginárias que fazem com que o autor destine seu dizer a um determinado interlocutor:

\footnotetext{
Mais amplamente, há um outro aspecto importante da representação do leitor no processo de leitura. O outro, isto é, o leitor na medida em que lê, se constitui, se representa, se identifica. A questão da compreensão não é só do nível da informação. Faz entrar em conta o processo de interação, a ideologia. (ORLANDI, 1996, p.185).
}

Por conta disso, a relação com os possíveis leitores reais será sempre tensa, visto que a leitura instaura-se como um espaço de interlocuçáo que, inevitavelmente, confronta sentidos derivados de formaçóes discursivas diferentes, as quais trazem diferentes posiçóes-sujeito mobilizando esses sentidos. Essa é a tensão necessária que instala o efeito-texto, sempre relativo ao momento em que ele é mobilizado por um sujeito-leitor em sua posiçãosujeito. A propósito disso, cabe destacar que a legibilidade do hipertexto está caracterizada pela navegaçáo na rede relacional de textos que configuram um percurso de leitura e que tornam o próprio conceito de ler em escritura potencial.

Dessa forma, o ato de navegar (ler) caracteriza-se por ser: a) uma tomada de posiçáo de um sujeito constituído pela evidência de ser fonte do sentido; b) um ato enunciativo-discursivo de uma posiçáo sujeito de "faz" escolhas de leitura construindo seu texto; c) um processo efêmero de legibilidade, já que esta não se concentra na materialidade da língua nem na intencionalidade de um autor.

A natureza do texto, nesses termos, é tensa, dialógica, pois assim como não pode abster-se do processo parafrástico (reformulação), não há como abrir mão da constante interlocução entre as posiçôes-sujeito engendradas na textualização, as posiçóes-sujeito do autor e do leitor e ainda as posiçóessujeito que se organizam no texto pelas relaçóes interdiscursivas. $\mathrm{O}$ texto não é mais o império de um significante, mas dos significados em toda sua pluralidade, não sendo objeto que se fecha, mas que, pelo contrário, abre um feixe de possibilidades.

Quando janelas abrem-se sobre janelas anteriores, quando um simples 
sintagma abre a possibilidade de outro percurso de leitura e de significação, não se está apenas colocando em tela a ação de clicar e de gerar uma rede de textos em torno de um assunto comum de pesquisa na web, mas está-se trabalhando com a noção de um sujeito que produz uma rede semântica, que retorna em links que não interessam, que retoma links que lhe são "mais interessantes" para o trabalho de leitura a que se propóe. É nesses momentos que um mapa de possibilidade se coloca, que uma teia (Figura 1) se tece em torno do assunto que originou a pesquisa.

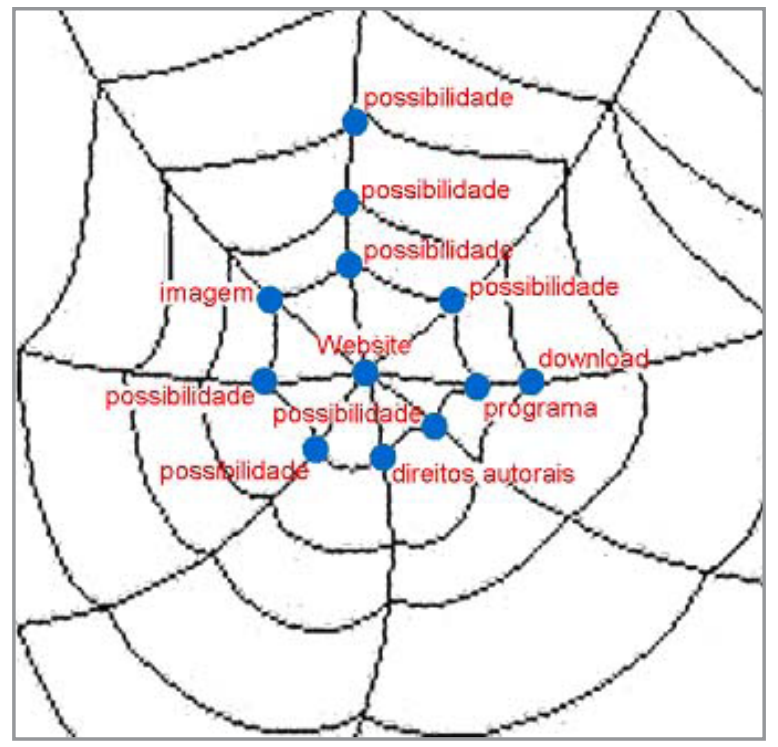

Figura 1: Hipertexto.

Fonte: <http://romanticos-conspiradores.ning.com/profiles/blogs/a-virtualizacao-do-texto>. Acesso em: dez. 2014.

Como vetores apontadores de caminhos, os links eletrônicos permitem que se pense em sua função como orientadores da constituição de um ideal de textualidade, já que cada elemento eletrônico é um elemento de linguagem (palavra, imagem) que está em relacionado ao assunto em pesquisa. A questão semântico-discursiva impôe-se ao pensarmos na constituição de um mapa de leitura-navegação e avaliarmos os padróes de leitura que os sujeitos realizam, pois "não é mais o leitor que vai se deslocar diante do texto, mas é o texto que, como um caleidoscópio, vai se dobrar e se desdobrar diferentemente diante de cada leitor" (LÉVY, 1999, p. 14). 
Portanto, o que até aqui foi exposto com a concepção de texto como efeito, como heterogeneamente constituído, leva-nos a situar um sujeitoleitor que produz sentidos vinculados a uma rede de relaçóes exteriores à materialidade puramente linguística. A linearização, sintagmatização de saberes exteriores que se projetam no texto escrito, pelas relaçóes interdiscursivas, conduz-nos, na análise do texto digital, em sua estrutura linkada, a refletir acerca de como essa rede de textos conectados produz essa sintagmatizaçáo. Não estamos nos referindo ao texto que compóe cada janela interligada, mas, justamente, ao que liga as janelas para formar os chamados hipertextos.

A qualidade do legível está, do ponto de vista aqui exposto, no gesto de construção de percursos de leitura por sujeitos que ocupam posiçóes-sujeito ligadas a uma materialidade histórica: o interdiscurso. Os hiperlinks, por sua vez, ultrapassam a definiçáo de apontadores de caminhos, de elementos endofóricos de textualidade para se colocarem como fenômenos de abertura semântica. A constante relação entre janelas de textos proporciona uma experiência de leitura como processo enunciativo e eleva os parâmetros de legibilidade com que os analistas de texto estão habituados a trabalhar. Ao aproximarmos a prática de leitura da prática enunciativa, estamos propiciando que se pense numa textualidade aberta em que a posiçãosubjetiva do leitor ultrapasse o conceito de interpretação.

\section{Referências}

GUIMARĀES, Eduardo (1995). Texto e Enunciação. Organon, v.9, n. 23, p. 65-69.

HAROCHE, Claudine. Fazer Dizer, Querer Dizer. São Paulo: Hucitec, 1992.

INDURSKY, Freda. Da heterogeneidade do discurso à heterogeneidade do texto e suas implicaçóes no processo de leitura. In: ERNST-PEREIRA, Aracy; FUNCK, Suzana Bornéo (Org.). A escrita e a leitura como práticas discursivas. Pelotas: Educat, 2001.

LANDOW, George P. Hipertexto: La convergência de La teoria critica contemporânea y La tecnologia. Barcelona: Paidós, 1995.

LÉVY, Pierre. O que é o Virtual? São Paulo: Editora 34, 1996. 
A Inteligência Coletiva: por uma antropologia do ciberespaço. Sáo Paulo: Loyola, 1999.

ORLANDI, Eni. A linguagem e seu funcionamento: as formas do discurso. Campinas: Pontes, 1996.

A leitura e os leitores. Campinas: Pontes, 1998.

Tânia Aiub - taniajfr@yahoo.com.br

Artigo recebido em 12 de dezembro de 2014

e aceito em 16 de janeiro de 2015. 